\title{
Assessment of Hospital Waste Management Practices in Public and Private Healthcare establishments of Rahim Yar Khan
}

\author{
Bismillah Sehar, ${ }^{1}$ Samina Waseem, ${ }^{2}$ Naeem ul Hassan ${ }^{3}$
}

\begin{abstract}
Background: Hospital waste is considered dangerous as it may pose undesirable effects on human health.

Objective: To assess the hospital waste management practices in private and public-sector healthcare establishments at district Rahim Yar Khan.

Methodology: This cross-sectional study was conducted in conveniently selected 34 healthcare establishments (HCEs) of district Rahim Yar Khan, from $1^{\text {st }}$ January to $30^{\text {th }}$ March 2018. Healthcare establishments included wards of a tertiary care hospital, basic health units, private clinics and hospitals of the district. Variables included were number of beds, color coding, hospital waste segregation at source, appropriate transportation vehicle, storage site and vehicles. SPSS version 21 was used for data entry and analysis.

Results: Twenty-six (76.5\%) of the healthcare establishments have waste segregation at source and $1(2.9 \%)$ of HCE have no proper color coding and 21 (61.8\%) of the HCEs have workers wearing protective gears and fifteen (44.1\%) have appropriate vehicle for waste transport. Waste disposal was incineration in nineteen $(55.89 \%)$ of HCEs. Eleven $(57.9 \%)$ of the public sector HCEs were following segregation. $(\mathrm{p}=0.00)$ In private sector method of disposal of waste was mostly land disposal 7 (46.7\%) while in public sector HCEs, was mostly incineration in $14(73.7 \% \%)$. $(p=0.00)$ and out of total $34 \mathrm{HCEs}$, training about handling and waste management were given in only one $(6.6 \%)$ of Private Hospitals.

Conclusion: Most of the healthcare establishments have a good waste segregation, baskets with color coding, individual bed side bins available however personal protective gears, waste transport system and waste disposal methods were deficient. There was a mixed pattern of individual steps of waste handling among private and public sector hospitals.
\end{abstract}

Key words: Hospital waste, Practices, Public, Private, Healthcare Establishments

Article Citation: Sehar B, Waseem S, Hassan N. Assessment of Hospital Waste Management Practices in Public and Private Healthcare establishments of Rahim Yar Khan. JSZMC 2020;11(1):34-39

\section{Introduction}

Hospital waste is defined as "any solid waste that is generated in the diagnosis, treatment, or immunization of human beings or animals, in research pertaining thereto, or in the production or testing of biological." ${ }^{1}$ In most of the developing countries, solid waste has not got that sufficient attention, which is necessary. In many countries, hazardous waste, which includes medical waste is usually handled and disposed of along with domestic waste, thus creating and a source of a great health risk in municipal workers, public and local environment. ${ }^{2}$ Solid waste handling or management is yet one of the major challenge for healthcare facilities where related staff working threre and surrounding population are unaware of the hazards it can cause. Perhaps the major cause of this is lack of awareness or lack of funds and labor for this purpose. In developing countries, awareness and information on hospital waste management practices and needs in terms of its segregation at the source, collection at source and storage in separate specified areas, purpose built transportation and appropriate disposal is lacking as well. ${ }^{3}$ There is a careless attitude regarding hospital waste and the practice of indiscriminate disposal of the hospital waste by healthcare establishments is wide spread, additionally laboratories and research institutions can contribute to the transmission of so many devastating diseases such as hepatitis and AIDS (HIV) for those who handle hospital and also among the general population. ${ }^{4}$ Inappropriate medical waste disposal incidents and the fear of acquired immunodeficiency syndrome have been constantly

1. Frontier Medical College \& Dental College, Abbottabad, Pakistan.

2. Department of Community Medicine, Sheikh Zayed Medical College/Hospital, Rahim Yar Khan, UHS, Lahore, Pakistan.

3. Medical Specialist, CMH, Rawalpindi, Pakistan.

Correspondence: Dr. Bismillah Sehar, Assistant Professor, Frontier Medical College \& Dental College, Abbottabad, Pakistan.

Email:drseharnaeem@gmail.com Received: 10-01-2019Ｒeviewed: 05-07-2019 
drawn national attention and so the actions, to medical or hospital waste management practices. Hospitals or health centers are setting where sick people of having different diseases and victims encountering accident are given healthcare provided by the medical experts. Every human being who faces any health problem, is expected to protect his or her life, by visiting the healthcare center. This is obviously the reason that these healthcare centers or establishments would generate wastes that are hazardous to human health and the environment. Medical waste includes the materials which are produced from the medical treatment and scientific research. ${ }^{6}$ Hospital waste management is described as the management of hospital waste, which is produced by hospitals using evidenced based procedure and techniques that control the spread of diseases. The lack of this management results in the spread of many diseases as both the infectious and noninfectious waste may mix up or is improperly handled. Hospital waste can be divided into either two main groups or into many categories based on their pathogenicity and other variables. WHO has classified it into: sharps, infectious, pathological, radioactive, pharmaceuticals and others. Improper waste management can lead to serious environmental pollution, unpleasant odors for humen being, and infestations by the insects, rodents and worms, and it could results in the transmission of diseases such as typhoid and viral hepatitis, through injuries which results from sharps or needles that are contaminated with human blood or secretions. The major sources of such type of wastes are mostly hospitals, clinics, laboratories, blood transfusion center and hemodialysis centers, maternity homes and mortuaries. ${ }^{7,8}$ Medical waste is also produced in amny other establishments like general practitioner and dental offices, acupuncture, home care services for the sick, drug injecting addicts. ${ }^{7}$ WHO has assigned methods for the management of hospital waste. It includes minimization, segregation, storage and treatment. Treatment of the hospital waste could be made by autoclave or burning by incineration. Final disposal should be made by sanitary landfills. Safe management of hospital waste generated at health-care establishments should include a cost wise assessment and rapid assessment procedure, a policy guidelines, guidance national plans for the management of waste from injection activities, management of waste at primary health care centers, management of waste produced from immunization, and in emergencies. ${ }^{8}$ In 2002, the results of WHO conducted an assessment in many developing countries and it reported that the proportion of the healthcare settings not using proper waste disposal methods is quite poor and ranges from $18 \%$ to $64 \%$.

Pakistan is currently in phase of creating demand by more and more awareness compaigns and has started implementing hospital waste management procedures and techniques. The concerted efforts are not upto the mark yet, and if the attitudes of the staff and the public towards this, is not changed, situasation is not going to change soon. ${ }^{10}$ The unauthorized reuse and recycling practice particularly of disposable syringes is a very serious problem in the world. It poses a potential danger to almost everyone. ${ }^{11}$ In many parts of Pakistan this visible mishandling has led to uncontrolled spread of disease. Keeping in mind this situation, and identify the problems and suggest appropriate medical waste management system, this research aimed on the objective to assess the practices of the hospital waste management methods practiced in healthcare establishments of district Rahim Yar Khan.

\section{Methodology}

This was a cross sectional study, carried out in the public and private sector healthcare establishments (Wards, Clinics and hospitals) of Rahim Yar Khan, January to March, 2018. A total of 34 healthcare establishments (hospitals, wards and clinics) were included by convenient sampling technique in this study. Owner/ In charge of public and private sector healthcare establishments were approached for data collections. Inclusion criteria: All the public and private healthcare establishments of district whose owner/ in charge who gave informed verbal consent for data collection. Exclusion criteria: Owner/ In charge who did not showed willingness for inclusion in study. Data was collected from owner/ In charge of the hospital by using a pretested predesigned questionnaire. Variables included were: Number of beds, Nature of hospital, Color coding of baskets, Segregation done, Presence of individual bins, Methods of disposal, training to waste handlers, and Number of persons. Data was presented on variables like; Number of beds of hospital, collection of waste, segregation of waste, disposal, transportation, and storage of waste. Mean and standard deviation for 
numerical variables like number of beds of hospital and Variables like hospital waste collection, segregation, and disposal were presented as percentage. SPSS version 21was used for data entry and analysis. Ethical approval was sought from Institutional Review Board and informed verbal consent was taken from hospital in charge.

\section{Results}

The total number of beds all 34 healthcare establishments (HCE) was $33 \pm 5$. Fifteen (44.1\%) of HCEs were private clinics and $19(55.9 \%)$ were public hospital wards. Over all thirty three $(97.1 \%)$ had proper color coding system available. Twenty-six $(76.5 \%)$ of the HCEs were having their hospital waste segregated at source. Individual bins were available in twenty-eight $(82.4 \%)$ of HCEs. Half of the HCEs i-e $50 \%$ of hospitals and clinics were using plastic containers. In twenty one (61.8\%) hospitals, sanitary workers had protective gears. (Table I) Face masks were being in practice by hospital waste handlers in nineteen $(55.9 \%)$ of the HCEs, followed by use of boots and hand gloves in five $(14.7 \%)$ and ten $(29.41 \%)$ respectively.

In only fifteen (44.1\%) out of thirty-four of HCEs, appropriate vehicle for transportation of waste from ward to storage site was available. In twentyfour $(70.6 \%)$ hospitals and clinics, storage site of the waste collected was present while in ten (29.4\%) hospitals, it was outside the hospital and clinic's premises. In only four $(11.8 \%)$ of HCEs, waste was collected most frequently 6 times a day while in three $(8.8 \%) 3$ times a day, in nine $(26.5 \%)$ twice a day and in eighteen $(52.9 \%)$ waste was collected once a day. In nineteen $(55.89 \%)$ out of 34 hospitals, waste was incinerated while in nine (26.47\%) and six (17.64\%), it was dumped in land disposal and openly burnt respectively.

A manager was allocated to look for the hospital waste management in twelve $(35.3 \%)$ of the HCEs (Hospitals and clinics). Waste was segregated at source in all fifteen (100\%) private-sector hospitals while in public-sector only $11(57 \%)$ of the hospitals followed the rule for segregation of waste. $(p=0.004)$ Proper color coding of bins was being done in fourteen $(93.3 \%)$ of Private Hospitals while all of the public-sector hospitals were following color coding with $100 \%$ results $(p=0.1)$. Regarding bins availability, all of the private hospitals were providing individual bins at each bed. Individual bins were available in only thirteen out of total nineteen of the public-sector hospitals. $(p=0.01)$ Appropriate vehicle for transportation of waste was absent in about $70 \%$ of the public-sector hospitals while in up to $60 \%$ of the private hospitals had appropriate transportation vehicle. $(p=0.09)$

Table I: Practices of waste segregation at source, color coding, bins for each beds, transport facility, training and waste disposal methods. $(n=34)$

\begin{tabular}{|l|c|c|}
\hline \multicolumn{1}{|c|}{ Variable } & Frequency & Percentage \\
\hline Waste Segregation at source \\
\hline Yes & $\mathbf{2 6}$ & $\mathbf{7 6 . 5}$ \\
\hline No & $\mathbf{8}$ & $\mathbf{2 3 . 5}$ \\
\hline Color Coding & $\mathbf{3 3}$ & $\mathbf{9 7 . 1}$ \\
\hline Yes & $\mathbf{1}$ & $\mathbf{2 . 9}$ \\
\hline No & $\mathbf{2 8}$ & $\mathbf{8 2 . 4}$ \\
\hline Individual Bins \\
\hline Yes & $\mathbf{6}$ & $\mathbf{1 7 . 6}$ \\
\hline No & $\mathbf{2 1}$ & $\mathbf{6 1 . 8}$ \\
\hline Protective gears \\
\hline Yes & $\mathbf{1 3}$ & $\mathbf{3 8 . 2}$ \\
\hline No & $\mathbf{1 5}$ & $\mathbf{4 4 . 1}$ \\
\hline Appropriate transport & $\mathbf{5 5 . 9}$ \\
\hline Yes & $\mathbf{1 9}$ \\
\hline No & $\mathbf{6}$ & $\mathbf{2 6 . 5}$ \\
\hline Method of Disposal \\
\hline Land disposal & $\mathbf{1 9}$ & $\mathbf{5 5 . 9}$ \\
\hline Incineration & $\mathbf{1 9}$ \\
\hline Open burning & $\mathbf{6}$ & \\
\hline
\end{tabular}


Table II: Comparison of private and public-sector healthcare establishments about waste segregation, disposal and training of healthcare handlers

\begin{tabular}{|c|c|c|c|c|c|}
\hline Variable & \multicolumn{4}{|c|}{ Waste Management Step } & Pvalue \\
\hline Segregation at source & Yes & No & \multicolumn{2}{|c|}{ Total } & \\
\hline Private & $15(100 \%)$ & $0(0 \%)$ & \multicolumn{2}{|c|}{$15(100 \%)$} & \\
\hline Public & $11(57.9 \%)$ & $8(42.1 \%)$ & \multicolumn{2}{|c|}{$19(100 \%)$} & \\
\hline Total & $26(76.5 \%)$ & $8(23.5 \%)$ & \multicolumn{2}{|c|}{$34(100 \%)$} & 0.004 \\
\hline Nature of Disposal & Land disposal & Incineration & Open burning & Total & \\
\hline Private & $7(46.7 \%)$ & $5(33.3 \%)$ & $3(20 \%)$ & $15(100 \%)$ & \multirow{3}{*}{0.002} \\
\hline Public & $2(10.5 \%)$ & $14(73.7 \%)$ & $3(15.8 \%)$ & $19(100 \%)$ & \\
\hline Total & $9(26.5 \%)$ & $19(55.9 \%)$ & $6(17.6 \%)$ & $34(100 \%)$ & \\
\hline Training given & Yes & No & \multicolumn{2}{|c|}{ Total } & \\
\hline Private & $1(6.6 \%)$ & $14(93.4 \%)$ & \multicolumn{2}{|c|}{$15(100 \%)$} & \\
\hline Public & $0(0 \%)$ & $19(100 \%)$ & \multicolumn{2}{|c|}{$19(100 \%)$} & 0.001 \\
\hline Total & $1(3 \%)$ & $33(97 \%)$ & \multicolumn{2}{|c|}{$34(100 \%)$} & \\
\hline
\end{tabular}

Figure I: Problems faced for hospital waste handling

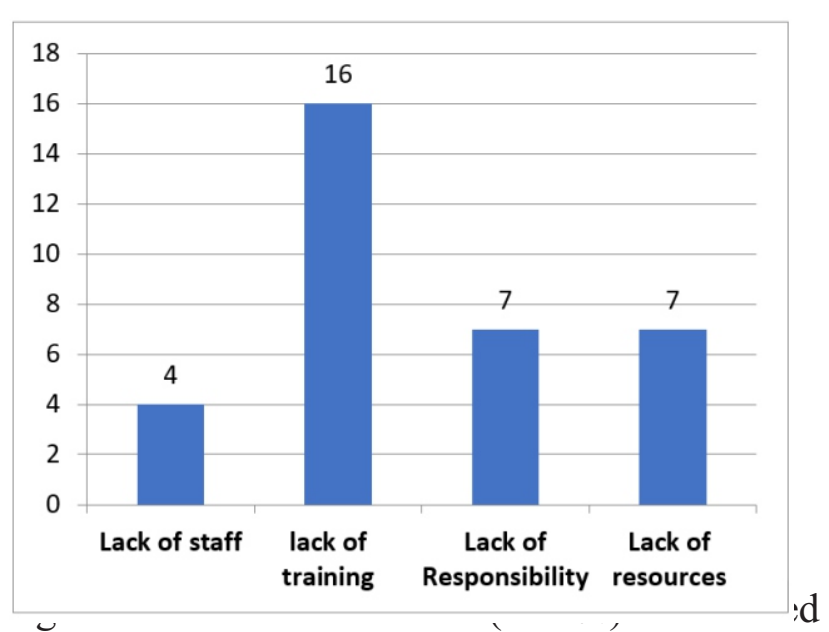

lack of training as the problem in effective waste management while seven (20.58\%) considered lack of resources as a problem. Seven $(20.58 \%)$ of total 34 of hospitals and clinics considered lack of responsibility as a problem in waste management while only four $(11.74 \%)$ regarded lack of staff as an issue.

Table II shows the practices of waste segregation at source, method of disposal of waste and traing about handling and waste management at private and public sector HCEs.

\section{Discussion}

In Pakistan the overall practices of hospital garbage disposal are poor and result in an incalculable spread of infectious diseases. ${ }^{10,11}$ Due to the insufficient number of workers, lack of training among those workers along with lack of proper equipment, proper garbage disposal poses to be a problem. In this study, methods of garbage disposal were noted by a convenient sampling technique. A total of 34 HCEs were surveyed, out of these 34 only 26 segregated waste.

In a study conducted in Karachi 8 teaching hospitals were surveyed out of which only 2 hospitals had proper waste management including segregation on spot and color coding. Other than that, few had incinerators working. ${ }^{12}$ This is comparable to our study in which $76.5 \%$ segregated the waste at source, $55 \%$ used an incinerator and $82.4 \%$ had individual bins. Whereas $2.9 \%$ had no color coding, and $23.5 \%$ were not segregated waste. Our study also concluded that 18 out of 34 used plastic bags whereas 19 used plastic containers and 1 used metal container. In 21 of these 34 hospitals, the sanitary workers were wearing protective gear and 13 were not. This gear included $79.4 \%$ wearing face masks, $29.4 \%$ wearing boots and $55.9 \%$ were wearing hand gloves.

In a study in Rawalpindi and Islamabad in Pakistan a total of ten hospitals were surveyed which included 6 public and 4 private hospitals. Neither had proper waste disposal methods and only 4 disposed of hazardous waste separately. There was no color coding and no waste disposal trolleys. Only one public sector hospital had an incinerator whereas the 
private hospitals maintained an open dumping wasteland. ${ }^{13}$ In another case study in Dental hospitals of Pakistan, Rawalpindi and Islamabad, a total of five hospitals were surveyed. Out of these five, four had color coding and segregation at source. When the incinerator facilities were surveyed 2 hospitals had incinerators whereas three didn't. Area of storage was present in only one hospital. ${ }^{14}$

In a study in Bahawalpur regarding medical waste managing practices, 48 hospitals were surveyed (24 public and 24 private). In public sector hospitals, only half of hospitals were segregating hospital and medical waste from other common waste while in private sector healthcare establishments it was practiced only in $16.6 \%$ settings. This was not even near to satisfactory situation and similar situation was noted in our study. Interestingly as in our study, separate area for segregation was labeled and practiced all public-sector hospitals and more than half (58\%) private sector hospitals. They reported that proper containers for the waste segregation, color coded baskets for types of hospital waste and use of protective gears by waste handlers in public and private sector was $100 \%, 75 \%, 33.3 \%$ and $58.3 \%$, $33.3 \%, 25 \%$ respectively. These findings are also close to our results in many aspects. Additionally, in public sector establishments, proper container for transport of waste within hospital and storage area for waste was present in all public-sector hospitals whereas, in private sector it was present in one half to one third of them. It was noted in that study that final disposal of the hospital waste was not upto mark in any hospital of both groups, with no incinerator in Bahawalpur city when study was being conducted. ${ }^{15}$

In study in Uttar Pradesh of India, the number of hospitals was 17, out of which 8 had incinerating facilities and only 3 had approval for biomedical waste disposal. This is comparable to our case study in which 34 hospitals were surveyed in which 24 had incinerating facilities. ${ }^{16}$

In a case study in Iran, 15 private hospitals were surveyed and the present situation of garbage disposal reviewed. Out of 15 hospitals two hospitals used containers without lids for transport of wastes and in 13 closed containers were used and 9 hospitals were equipped with incinerators and $6(40 \%)$ of them have operational problems. ${ }^{17}$ Another case study in Brazil was done in which the survey determined that in $98 \%$ of the health centers and $95 \%$ of clinical laboratories the segregation of waste was done. This is comparable to our segregation practices in that study only 26 (76.5\%)of them have their waste segregated at the source and $8(23.5 \%)$ hospitals don't do so. ${ }^{18}$

\section{Conclusion}

Most of the healthcare establishments that included wards, clinics and basic health units, have a good waste segregation, baskets with color coding, individual bed side bins available in our study however personal protective gears, waste transport system and waste disposal methods were insufficient. There was a mixed pattern of individual steps of waste handling among private and public sector hospitals, some steps like segregation of waste, and individual bed side bins were practiced significantly better in private hospitals whereas, waste disposal by incineration and transport availability for waste was better in public hospitals.

Authors Contribution: BS: Conception of work and Design of Work. SW: Drafting and Revising. NH: Analysis of data and drafting.

All the authors gave final approval for publication and agreed to be accountable for all aspect of work.

Conflict of Interest: None

Sources of Funding: Self

\section{References}

1. Pakistan Medical Waste Act 1988. Availalbe from;www.health.punjab.gov.pk > PHSRP-EMWMPFINA

2. Rasheed, Shahida Iqbal, Saira Baig, Lubna, Mufti, Kehkashan. Hospital Waste Management in theTeaching Hospitals of Karachi. JPMA 2015; 55; 192-5.

3. Bdour A, Altrabsheh B, Hadadin N, Al-Shareif M. Assessment of medical wastes management practice: a case study of the northern part of Jordan. Waste Manag 2007; 27(6): 746-59

4. Wafula ST, Musiime J, Oporia, F. Health care waste management among health workers and associated factors in primary health care facilities in Kampala City, Uganda: a cross-sectional study. BMC Public Health 2019; 19; 203

5. Temitope and Funmbi. Availability of Health care centers and its waste management in AKURE, South Western Nigeria,. BJESBS 2017; 19(1): 1-8

6. Hospital waste management \& environmental assessment in Pakistani selected facilities Guidelines for Safe and Environmental Management, USAID, Dec 2008

7. Safe management of wastes from health-care activitiesWorld Health Organization. Available at; www,http/who.it./ 
8. Management of Waste. Retrieved from;https:// www.who.int/water_sanitation_health/facilities/waste /safe-management-of-wastes-from-healthcareactivities/en/2014

9. Shinee, Enkhtsetseg, Gombojav, Enkhjargal, Nishimura, Akio Hamajima, Nobuyuk Ito, Katsuki. (2008). Healthcare waste management in the capital city of Mongolia. Waste management (New York, N.Y.). 28.435-41. 10.1016/j.wasman.2006.12.022.

10. Kumar R, Khan EA, Ahmed J, Khan Z, Magan M, Nousheen, Mughal MI.Healthcare waste management (HCWM) in Pakistan: current situation and training options. J Ayub MedCollege Abbottabad 2010 OctDec; 22(4): 101-5.

11. Ullah JH, Ahmed R, Malik JI, Khan MA. Outcome of 7S, TQM technique for healthcare waste management. J Coll Physicians Surg Pak 2011 Dec; 21(12): 731-4)

12. Shahida Rasheed, Saira Iqbal, Lubna A. Baig, Kehkashan Mufti. Hospital Waste Management in the teaching Hospitals of Karachi. Journal of the Pakistan Medical Association 2005; 55(5);324

13. Sanwal Ali, Usman Mahmood, Asad Ullah Malik, Farrukh Aziz, Roshaan Bin Naghman, Ishtiaq Ahmed. Current Hospital Waste Management Practices in Pakistan: Case Study and Curative Measures. Public Health and Preventive Medicine 2015;1;65
14. Zaib N, Umer N. And Masood R. Waste Management At Dental Hospitals Of Rawalpindi - Islamabad region Department Of Oral Pathology, Islamic International Dental College, Riphah International University, Islamabad Pakistan, 2015

15. Samina Badar, Muhammad Akram Saeed, Seema Yasmeen, Wajahat Hussain, Mohammad Asim Amjad. Health Care Waste Management Practices in Public and Private Sector Hospitals.Quaid-i-Azam Medical College, Bahawalpur. Journal of Rawalpindi Medical College.2014;18(1);145-7

16. Saurabh Gupta, Ram Boojh. Bio medical waste management practices at Balrampur Hospital, Lucknow, India. Waste Management and Research, 2006; 26; 584-9

17. Mehrdad Askarain, Mehmood Valiki. Results of hospital waste survey in private hospitals in Fars Province, Iran. Waste Management 2004;24;347-52. doi: 10.1016/j.wasman. 2003.09.008

18. C.E. Da Silva, A. H, A.E. Hoppe, M.M.Ravanelo, N. Mello. Medical waste management in South of Brazil. Waste Management 2005;https://doi.org/10.1016/ j.wasman.2004.03.002 